\title{
GESTÃO FINANCEIRA DE PROPRIEDADE DE AGRICULTURA FAMILIAR
}

Flavio Alberto Oliva, Maycon Amim Vieira

Universidade do Oeste Paulista, Faculdade de Ciências Agrárias de Presidente Prudente, Presidente Prudente, SP; E-mail: flavioaoliva@gmail.com

\section{RESUMO}

A agricultura familiar é responsável por 33\% do PIB Agropecuário e $74 \%$ da mão de obra empregada no campo. Este estudo tem como objetivo criar um modelo de gestão financeira para uma propriedade rural de agricultura familiar. O Sítio Cristo Redentor de Presidente Venceslau-SP serviu como modelo. Foi elaborada uma projeção partindo dos investimentos já realizados na propriedade bem como a necessidade futura de injeção de recursos. A análise do projeto trouxe a luz do VPL positivo de R\$47.247,15, TIR de 19,77\% e o Payback de 4 anos, demonstrando a viabilidade da propriedade. A gestão financeira aliada às técnicas de administração rural, permite ao agricultor familiar prever o futuro financeiro e escolher os investimentos que trarão melhor resultado.

Palavras-chave: Agricultura Familiar, Gestão Financeira, Custo, Faturamento, Investimento.

\section{FINANCIAL MANAGEMENT OF PROPERTY OF FAMILY AGRICULTURE}

\begin{abstract}
Family farming is responsible for $33 \%$ of GDP Agricultural and $74 \%$ of the workforce employed in the field. This study aims to create a model of financial management for a farm family farming. Farm Christ Wenceslas-SP President of Redeemer served as a model. A projection starting from the investments already made in the property and the future need for resources injection was developed. The project analysis brought to light the positive NPV of $R \$ 47,247.15$, IRR of $19.77 \%$ and payback of 4 years, demonstrating the viability of the property. The financial management coupled with rural management techniques, allows the family farmer predict the financial future and choose investments that will bring better results.
\end{abstract}

Keywords: Family Agriculture, Financial Management, Cost, Income, Investment. 


\section{INTRODUÇÃO}

Empresa rural é definida por Marion (2000), como aquela que explora a capacidade produtiva por meio de cultivo do solo. Já Souza et. al. (1995), define como um organismo econômico e social que se propõe a produzir bens ou serviços, o mesmo ainda define que a empresa rural demanda do produtor decisões sobre aspectos internos e externos da propriedade, na qual influenciam diretamente na sua implantação e controle.

Segundo Reis (2002), o setor agropecuário é marcado por algumas características que o diferencia dos demais. O setor é altamente competitivo, com heterogeneidade de gestão e tecnologia, com atividades que apresentam margens estreitas e com rentabilidade de média a baixa. Souza et. al. (1995) relata que os riscos da atividade são maiores que em outros setores da economia devido à dependência de fatores ambientais, além da flutuação de preço de mercado.

Além de assegurar o importante papel do agronegócio como destaque no Produto Interno Bruto (PIB), a permanência do país como um dos principais exportadores, depende necessariamente de planejamento das propriedades rurais. Começando pela administração das propriedades como uma empresa, controlando os custos de produção para análise de pontos críticos, além de priorizar o investimento em insumos e a verticalização da produção.

Segundo o Ministério do Desenvolvimento Agrário (2013), a agricultura familiar é responsável por 33\% do PIB Agropecuário e $74 \%$ da mão de obra empregada no campo. Sendo assim, esse setor que atualmente carece de planejamento e políticas publicas eficazes, constitui um dos principais pilares do PIB brasileiro, requer que as propriedades passem a ser gerenciadas como empresas.

Uma das principais normas que têm afetado a exportação dessas empresas familiares é o Protocolo EurepGap, na qual descreve os requisitos essenciais de acordo com as Boas Práticas de Agricultura (BPA), que tem como objetivo a segurança alimentar, a proteção do meio ambiente, o bem estar humano, segurança e saúde ocupacional e o bem estar animal. Outra norma é a ISO (Organização Internacional de Normatização) 14000 que normatiza a gestão ambiental.

Sendo assim, este trabalho tem como objetivo criar um modelo de gestão financeira para uma propriedade rural de agricultura familiar, aplicando técnicas de administração rural, gerenciando a estrutura administrativa da empresa, com planejamento simplificado, através de técnicas relativas ao processo de elaboração de projetos agropecuários e agroindustriais.

\section{METODOLOGIA}

O estudo propôs-se a contribuir na organização das informações obtidas em planilhas adequadas possibilitando assim a apuração confiável dos custos e consequentemente proporcionando informações fidedignas para a estruturação de informações necessárias à gestão da propriedade que estejam relacionadas aos custos. $O$ estudo baseou-se em informações e dados quantitativos, no entanto, possui também caráter qualitativo à medida que se utilizou dessas informações para análises financeiras, econômicas e tomadas de decisões.

\section{RESULTADOS}

Os investimentos, após os cinco anos, somarão $\mathrm{R} \$ 260.799,45$ (Tabela 1 ), sendo $\mathrm{R} \$$ 180.000 em aquisições de novos animais, $\mathrm{R} \$ 10.000,00$ na aquisição do resfriador, $\mathrm{R} \$ 3.863,42 \mathrm{em}$ equipamento para IATF, aquisição da ordenha mecânica por $\mathrm{R} \$ 6.300,00, \mathrm{R} \$ 32.390,53$ para a construção do galpão de ordenha, instalação para bezerros, $\mathrm{R} \$ 9.000,00$, A reforma das pastagens foi estimada em $R \$ 16.178,53$ e as cercas para a divisão dos piquetes em $R \$ 3.067,00$. 
Tabela 01. Investimentos

\begin{tabular}{|c|c|c|}
\hline Custos Operacionais Fixos & & Total \\
\hline Aquisição de dez matrizes & $\mathrm{R} \$$ & $80.000,00$ \\
\hline Aquisição do Resfriador & $\mathrm{R} \$$ & $10.000,00$ \\
\hline Aquisição do Equipamento de Inseminação & $\mathrm{R} \$$ & $3.863,42$ \\
\hline Aquisição da Ordenha Mecânica & $\mathrm{R} \$$ & $6.300,00$ \\
\hline Construção do Galpão de Ordenha & $\mathrm{R} \$$ & $32.390,53$ \\
\hline Instalação do Bezerreiro Adequado & $\mathrm{R} \$$ & $9.000,00$ \\
\hline Reforma da Pastagem & $\mathrm{R} \$$ & $16.178,50$ \\
\hline Divisão dos Piquetes & $\mathrm{R} \$$ & $3.067,00$ \\
\hline
\end{tabular}

No primeiro ano, os investimentos serão de $\mathrm{R} \$ 10.000,00$ na aquisição do resfriador, $\mathrm{R} \$$ $3.863,42$ na aquisição do equipamento de inseminação, $R \$ 7.444,00$ e $R \$ 1.745,00$ na reforma das

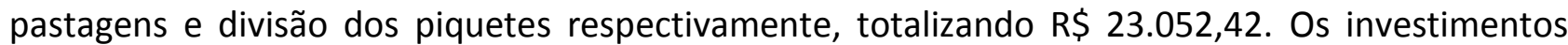

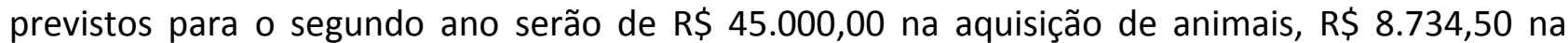
reforma das pastagens e $\mathrm{R} \$ 1.322,00$ na divisão dos piquetes, totalizando $\mathrm{R} \$ 55.056,00$.

No terceiro ano, serão investidos $R \$ 45.000,00$ na aquisição de animais novos e $R \$$ $9.000,00$ na instalação dos bezerreiros, totalizando $\mathrm{R} \$ 54.000,00$. No quarto ano, os investimentos serão de $\mathrm{R} \$$ 45.000,00 na aquisição de animais e $\mathrm{R} \$ 32.390,53$ na construção do galpão de

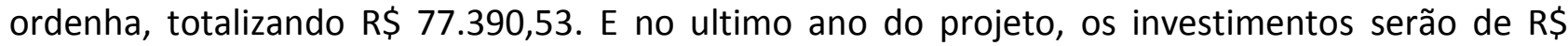
45.000,00 na aquisição de novos animais e $\mathrm{R} \$ \mathbf{6 . 3 0 0 , 0 0}$ na aquisição da ordenha mecânica, totalizando $\mathrm{R} \$ \mathrm{R} \$ 51.300,00$.

Os custos variáveis, ao termino do quinto ano, estão projetados para $\mathrm{R} \$ 241.347,76$ (Tabela 2), sendo $\mathrm{R} \$ 10.432,00$ na aquisição de equipamento para inseminações artificiais em tempo fixo, $R \$ 220.915,76$ em suplementação animal e $R \$ 10.000,00$ em medicamentos.

Tabela 02. Custos variáveis

\begin{tabular}{|c|c|}
\hline Custos Variáveis & Total \\
\hline Inseminação artificial & $\mathrm{R} \$ \quad 10.432,00$ \\
\hline Suplementação Animal & $\mathrm{R} \$ 220.915,76$ \\
\hline Medicamentos & $\mathrm{R} \$ \quad 10.000,00$ \\
\hline Total & $\mathrm{R} \$ 241.347,76$ \\
\hline
\end{tabular}

No primeiro ano, os custos variáveis são de $\mathrm{R} \$ 1.043,20$ com inseminação artificial, $\mathrm{R} \$$ 14.795,28 em suplementação animal e $R \$ 1.000,00$ em medicamentos, totalizando $R \$ 16.838,48$. Os custos variáveis, no segundo ano, foram calculados em $\mathrm{R} \$ 1.564,80$ para inseminação artificial, $\mathrm{R} \$ 2$ 29.590,55 em suplementação animal e $\mathrm{R} \$$ 1.500,00 em medicamentos, totalizando $\mathrm{R} \$$ $32.655,35$.

No terceiro ano serão $\mathrm{R} \$ 2.086,40$ em inseminação artificial, $\mathrm{R} \$$ 44.385,83 em suplementação e $\mathrm{R} \$ 2.000,00$ em medicamentos, totalizando $\mathrm{R} \$ 48.472,23$. No quarto ano, os custos variáveis serão de $\mathrm{R} \$ 2.608,00$ para inseminação artificial, $\mathrm{R}$ \$ 59.181,00 em suplementação e $\mathrm{R} \$ 2.500,00$ em medicamentos, totalizando $\mathrm{R} \$ 64.289,10$.

E no quinto e ultimo mês, os custos variáveis serão de $\mathrm{R} \$ 3.129,60$ para inseminação artificial, $\mathrm{R} \$ 72.963,00$ em suplementação e $\mathrm{R} \$ 3.000,00$ em medicamentos, totalizando $\mathrm{R}$ \$ $79.092,60$. Os custos de oportunidade (Tabela 3 ) serão de $\mathrm{R} \$ \mathbf{6 . 6 0 8 , 0 0}$ por ano a uma taxa de juros de $8 \%$ a.a. sobre um capital de $\mathrm{R} \$ 82.600,00$. 
Tabela 03. Custos de oportunidade

\begin{tabular}{lcc}
\hline Custo de Oportunidade & Total \\
\hline Capital & $\mathrm{R} \$$ & $82.600,00$ \\
Taxa de Juros (8\% a.a.) & $40 \%$ \\
\hline Total do Custo de Oportunidade & $\mathbf{R \$}$ & $\mathbf{3 3 . 0 4 0 , 0 0}$ \\
\hline
\end{tabular}

Ao final dos cinco anos, os custos de oportunidade totalizarão em $\mathrm{R} \$ 33.040,00$, representando $40 \%$ do capital investido de $\mathrm{R} \$ 82.600,00$.

As depreciações após os cinco anos chegarão a um total de R\$97.851,48 (Tabela 4), sendo $\mathrm{R} \$ 78.000,00$ depreciações dos animais, $R \$ 1.545,36$ da ordenha mecânica, $R \$ 4.000,00$ do resfriador, $\mathrm{R} \$ 1.295,62$ do galpão de ordenha, $\mathrm{R} \$ 720,00$ do bezerreiro, $\mathrm{R} \$ 11.195,90$ das pastagens e $\mathrm{R} \$ 1.094,60$ das cercas elétricas.

Tabela 04. Depreciação depois dos cinco anos.

\begin{tabular}{lc}
\hline Depreciação em $\mathbf{5}$ anos & Total \\
\hline Animais & $\mathrm{R} \$ \mathbf{7 8 . 0 0 0 , 0 0}$ \\
Ordenha & $\mathrm{R} \$ 1.545,36$ \\
Resfriador & $\mathrm{R} \$ 4.000,00$ \\
Galpão de Ordenha & $\mathrm{R} \$ 1.295,62$ \\
Bezzerreiro & $\mathrm{R} \$ 720,00$ \\
Pastagem & $\mathrm{R} \$ 11.195,90$ \\
Cerca elétrica & $\mathrm{R} \$ 1.094,60$ \\
\hline Total & $\mathrm{R} \$ \mathbf{9 7 . 8 5 1 , 4 8}$ \\
\hline
\end{tabular}

A depreciação dos animais será de $20 \%$ a.a., sendo no primeiro e segundo anos de $\mathrm{R} \$$ $12.000,00$. No terceiro ano em diante, somente terá depreciação os animais adquirido no segundo ano, pois os animais que estavam na propriedade já atingiram o valor de descarte, ou seja, o terceiro o ano, a depreciação dos animais será de $\mathrm{R} \$ 9.000,00$. No quarto ano será de $\mathrm{R} \$$ $18.000,00$ e no quinto de $\mathrm{R} \$ 27.000,00$.

A ordenha mecânica e o resfriador terão uma depreciação de $10 \%$ a.a., ou seja, $\mathrm{R} \$ 386,34$ e $\mathrm{R} \$ 1.000,00$ por ano respectivamente, a partir do segundo ano.

Já o galpão de ordenha e o bezerreiro terão uma depreciação de $4 \%$ a.a., sendo um valor de $\mathrm{R} \$ 1.295,62$ e $\mathrm{R} \$ 360,00$ por ano respectivamente, o galpão de ordena a partir do quinto ano e o bezerreiro a partir do quarto ano. A pastagem terá uma depreciação de $20 \%$ a.a., ou seja, $\mathrm{R} \$$ $1.488,80$ no segundo ano e a partir do terceiro ano de $\mathrm{R} \$ 3.235,70$.

A cerca elétrica será depreciada em $10 \%$ a.a., sendo $R \$ 174,50$ no segundo ano e a partir do terceiro ano $R \$ 306,70$. Ou seja, o primeiro ano terá um total de depreciação de $R \$ 12.000,00$, o segundo ano de $\mathrm{R} \$ 15.049,64$, o terceiro ano de $\mathrm{R} \$ 13.928,74$, o quarto ano de $\mathrm{R} \$ 23.288,74$ e no quinto ano de $R \$ 33.584,36$.

O projeto em questão terá custo variável de $\mathrm{R} \$ 241.347,76$ (Tabela 5) e investimentos de $\mathrm{R} \$ \mathbf{2 6 0 . 7 9 9 , 4 5}$, resultando no custo operacional total de $\mathrm{R} \$ \mathbf{5 0 2 . 7 9 9 , 4 5}$. Já o custo de oportunidade será de $\mathrm{R} \$ 33.040,00$, totalizando $\mathrm{R} \$ 535.187,21$. 
Tabela 05. Resultados econômicos

\begin{tabular}{ll}
\hline Custo operacional variável & $\mathrm{R} \$ 241.347,76$ \\
Investimentos & $\mathrm{R} \$ 260.799,45$ \\
Custo operacional total & $\mathrm{R} \$ 502.147,21$ \\
Custo de Oportunidade & $\mathrm{R} \$ 33.040,00$ \\
Custo total & $\mathrm{R} \$ 535.187,21$ \\
Receitas Totais & $\mathrm{R} \$ 717.400,00$ \\
Lucro operacional & $\mathrm{R} \$ 215.252,79$ \\
\hline Lucro Total & $\mathrm{R} \$ \mathbf{1 8 2 . 2 1 2 , 7 9}$ \\
\hline
\end{tabular}

A receita esta prevista para $\mathrm{R} \$ 717.400,00$, sendo assim, resultará um lucro operacional de $\mathrm{R} \$ 212.252,79 \mathrm{e}$ um lucro total de $\mathrm{R} \$ 182.212,79$.

\section{DISCUSSÃO}

O projeto em questão apresentou VPL (Valor Presente Liquido) positivo de $\mathrm{R} \$ 47.247,15$, ou seja, demonstrou viabilidade.

A TIR de 19,77\% vem corroborar com esse diagnóstico onde o capital investido terá um retorno de $19,77 \%$, ou seja, mais que o dobro da poupança. Se o limitador desse projeto fosse o tempo, o Payback evidencia que o retorno desse capital se concretiza em 4 anos, ou seja, dentro dos cinco anos de desenvolvimento do projeto já teria o investimento de volta.

Por meio das analises financeiras, constatou-se que o projeto e viável.

Segundo Reis (2002), essa propriedade será estável e com capacidade de crescer no médio e longo prazos. Economicamente, essa propriedade terá o lucro supernormal e/ou lucro econômico, ou seja, a mesma estará obtendo retornos maiores que as melhores alternativas de emprego de capital.

\section{CONCLUSÃO}

Os controles administrativos de uma empresa rural são de grande valia, pois, não há sentido a empresa ter capacidade produtiva, produto de qualidade, espaço no mercado e não dispor de controles gerenciais rigorosos e confiáveis, portanto, é imprescindível o controle do processo produtivo bem como os processos gerenciais de forma a controlar custos e identificar os produtos mais rentáveis e atrativos à empresa.

Nessa ótica o presente trabalho se propôs a identificar os custos e a necessidade de investimentos bem como auxiliar na organização das informações geradas por um controle confiável dos custos e consequentemente pudesse proporcionar informações fidedignas para a estruturação de informações necessárias para a gestão da propriedade. As análises das demonstrações econômico-financeiras evidenciaram a viabilidade do empreendimento.

\section{REFERÊNCIAS}

ACBP. Guia de Construções Rurais à Base de Cimento. 2016. Disponível em: <http://www.abcp.org.br/cms/download/?search=Constru\%C3\%A7\%C3\%A30\%20rural>. Acesso em: 03.jun.2016.

ALDAY, H. E. C. O Planejamento Estratégico Dentro do Conceito de Administração Estratégica. v.3. Curitiba: FAE, 2000,

ANTUNES, L. M., RIES, L. R. Gerência Agropecuária. Guaíba: Agropecuária Ltda. 2001.

BORGES, I., BARBOSA, F. A., ALBUQUERQUE, F. H. M. A. R. Planejamento e Gestão de Sistemas de Produção, In: SIMPÓSIO MINEIRO DE OVINOCULTURAM. 4 ed. Lavras: UFLA, 2005. 
CHUDLEIGH, P. D. Análise de Investimento. In: SEMINÁRIO SOBRE A APLICAÇÃO DE UM ENFOQUE DE SISTEMAS NA PESQUISA DE PRODUÇÃO ANIMAL, 1 ed. Brasília: Embrapa/CNPGC, 1982.

. Estudo Sobre a Eficiência Econômica e Competividade da Cadeia Agroindustrial da Pecuária de Corte no Brasil. Brasília: IEL/CNI/SEBRAE, 2000.

MARION, J. C. Contabilidade Rural. São Paulo: Atlas. 2000.

MDA. ONU lança Ano Internacional da Agricultura Familiar nesta sexta-feira. 2013. Disponível em: <http://www.brasil.gov.br/governo/2013/11/onu-lanca-ano-internacional-da-agricultura-familiarnesta-sexta-feira>. Acessado em: 15.maio.2016.

MFRURAL. Instalações Rurais: Bezerreiro. 2015. Disponível em: <http://www.mfrural.com.br/detalhe/creep-feeding-movel-e-bezerreiro-individual-183737.aspx>. Acessado em: 06.jun.2016.

NOGUEIRA, E. Análise de Investimentos. In: BATALHA, M. O. Gestão Agroindustrial. 3 ed. São Paulo: Atlas, 2001.

REIS, R. P. Fundamentos de Economia Aplicada. Lavras: UFLA/FAEPE, 2002.

SANTOS, G. J.; MARION, J. C.; SEGATTI, S. Administração de Custos na Agropecuária. São Paulo: Atlas, 2002.

SENAR. Ensino a Distância. 2016. Disponível em: <http://ead.senar.org.br>. Acessado em: 07.jun.2016.

SOUZA, R.; GUIMARÃES, J. M. P.; MORAIS, V. A. A Administração da Fazenda. 5 ed. São Paulo: Globos, 1995. 